\title{
Pedagogia das diferenças e a formação docente em tempos de necropolíticas
}

\author{
Pedagogy of differences and teacher training in necropolital's times
}

\author{
Pedagogía de las diferencias y formación del profesorado en tiempos de necropolítica
}

Heloisa Andreia de Matos Lins - Faculdade de Educação da UNICAMP | Depto.de Psicologia Educacional | Campinas | SP | Brasil | E-mail: hmlins@ unicamp.br | (1orci

Gabriela Antunes Marques - Universidade Estadual de Campinas | Estudante Graduanda do curso de Letras - habilitação ensino-aprendizagem de Português como segunda língua | Campinas | SP | Brasil | Email: g168216@dac.unicamp.br | (1) овсі

Homero Dantas Ragnane - Universidade Estadual de Campinas | Mestrando no Programa de PósGraduação em Educação | Campinas | SP | Brasil | E-mail: homeroragnane @ gmail.com | (1) orcid

Resumo: O artigo discute uma proposta de formação de professores para a Educação Básica, centrada na chamada Pedagogia das Diferenças, e destaca os principais sentidos construídos e trazidos à tona nesse processo de ensino-aprendizagem, em tempos de militarização do ensino no Brasil. O trabalho caracteriza-se como um relato de experiência em que são retomadas as memórias e reflexões de estudantes de licenciatura sobre seus percursos em estágios supervisionados. Diante desse contexto, os principais resultados evidenciam que alguns movimentos de (re) invenção da escola e do currículo tornam-se possíveis pelo agenciamento de desejos dos que fazem a escola e dos que nela irão atuar profissionalmente, em direção à assunção das diferenças como modo de resistência às necropolíticas.

Palavras-chave: Formação docente. Diferenças. Necropoder. Escolas cívico-militares.

Abstract: This paper discusses the proposal of teacher training for basic education, centered on the so-called Pedagogy of Differences, and highlights the main meanings created and emerged in this teaching-learning process, in times of militarization of education in Brazil. The work is characterized as an experience report in which the memories and reflections of undergraduate students about their paths in supervised internships are resumed. Given this context, the main results of a teacher training process show that some movements of (re)invention of the school and of the curriculum are made possible by mediating the wishes of those who are part of the school community and those who will act professionally in it, towards the assumption of differences as a way of resistance to necropolitics.

Keywords: Teacher training. Differences. Necropower. Military-civic schools. 
LINS, Heloisa Andreia de Matos; MARQUES, Gabriela Antunes; RAGNANE, Homero Dantas. Pedagogia das diferenças e a formação docente em tempos de necropolíticas.

Resumen: El artículo analiza una propuesta para la formación docente centrada en la llamada Pedagogía de las diferencias y destaca los principales significados construidos y sacados a la luz en este proceso de enseñanza-aprendizaje, en tiempos de militarización de la enseñanza en Brasil. En este contexto, los principales resultados de un proceso de capacitación docente muestran que algunos movimientos de (re) invención de la escuela y el plan de estudios se hacen posibles a través de la agencia de los deseos de quienes hacen la escuela y de quienes trabajarán profesionalmente, en particular, hacia la asunción de diferencias como una forma de resistir la necropolítica.

Palabras clave: Formación docente. Diferencias. Necropoder. Escuelas cívico-militares. 
[...] Em períodos de crise é fácil oferecer propostas imediatistas embrulhadas em formatos autoritários [...] (SCHWARCZ, 2019, p. 158).

[...] O centro da briga histórica que se trava à beira do despenhadeiro e talvez nos afaste da barbárie são o afeto e o imaginário das crianças e dos adolescentes (seu mundo valorativo, simbólico-cultural e psicológico) [...] (SOARES, 2019, p. 211).

\section{O papel da Pedagogia das Diferenças como possibilidade contra-hegemônica à domesticação e às violências}

Concebendo que as diferenças não se referem ao caráter negativo da identidade ou a algo que os indivíduos devem se desfazer, para poder "aprender como os outros", como pontua Skliar (2015), o presente artigo discute aspectos sobre as recentes políticas públicas para a educação no país, destacadamente a militarização das escolas, a partir de um processo de formação de professores, no âmbito de uma universidade pública estadual paulista. O curso assume como pressuposto que as diferenças não são atributos intrínsecos aos indivíduos, mas de relacionamentos, do que fazemos com os outros, como os nomeamos e podemos/ desejamos compreendê-los ou julgá-los, inclusive nas instituições educacionais. A proposta em questão, portanto, tem se pautado numa concepção socioantropológica das diferenças (então, de sua concepção como potência e não como falta).

Tal processo esteve voltado para a composição de olhares atentos às práticas educativas colonizadoras/normalizantes dos modos de existência e para a proposição de alternativas diante de tais processos que compreendem (e exigem, via de regra) apenas a mesmidade das crianças e jovens: do(s) outro(s), do(s) considerado (s) "diferente"(s). Nesse ínterim, concebe a participação ativa dos(as) envolvidos(as) num processo formativo de invenção contra-hegemônica e de aberturas às diferenças, com base em seus próprios temas de interesse (afeitos às questões de classe, raça/etnia e gênero/sexualidade, centralmente). Sem receituários ou caminhos seguros, vimos assumindo que o ensinar é um ato de partida e não de chegada e que o aprender assume o ignorar como modo de buscar e criar, em pleno contraste com as políticas da mesmidade defendidas atualmente pelo governo federal.

O desejo do movimento e das (re)descobertas é que parece brotar daí, apesar das adversidades concretas ao ser professor(a) no Brasil, em qualquer nível de ensino, quando se assume e defende práticas efetivamente democráticas, num momento em que o país acompanha 
as propostas e implementações da militarização nas escolas e no ensino, dentre outras investidas conservadoras e, muitas vezes, violentas, diante das comunidades já excluídas. A proposta de formação discute, portanto, a disciplinarização das crianças e da juventude, na direção do que seria uma sociedade punitiva, conforme perspectiva foucaultiana (KRAWCZYK, 2018; CÁSSIO, 2019), ainda que seja pelo clima policialesco gerado por essas (e outras) iniciativas que ainda não foram totalmente implantadas nas instituições de ensino. A dificuldade governamental gerada também por uma questão orçamentária, evidentemente, como destaca Moretti (2019). São narrativas alardeadas como solução aos problemas do ensino (mas não só, principalmente pelo senso comum, em função de argumentos como aumento da violência, da "falta de disciplina", envolvimento com drogas, piora do rendimento escolar, etc. ${ }^{1}$ ).

Como também argumentado por Ricci (2019): “A militarização escolar segue um roteiro midiático focado na espetacularização dos casos de violência [...]” (p. 108). O autor também destaca um importante dado: "A adoção da militarização escolar em diversas regiões do país não diminuiu os casos de violência envolvendo estudantes" (p. 109), o que evidencia um sintomático contrassenso social.

É curioso observar que, sob o âmbito da defesa da "civilidade, patriotismo e disciplina", como bem analisa Schwarcz (2019), o Brasil, em tempos de crise, mostra reincidentemente uma "veia autoritária". Assim, discursos (palavras de ordem, repetidas à exaustão) que apresentam "soluções fáceis", tendem a ter quase imediata adesão, como destaca a autora. No caso da militarização das escolas, não está sendo diferente: lida-se com os sintomas e não com as causas dos problemas.

Neste cenário, ainda que haja flagrante incoerência sobre o "desvio de função da política e dos órgãos militares em prover esse serviço público, inclusive considerando que não têm dado conta de cumprir com sua função primária, na segurança pública”, como ressalta a coordenadora do Comitê da Campanha no Distrito Federal, Catarina de Almeida Santos (apud BARROSO, 2018), havia - até início do mês de julho de 2019 - evidentes violações à Constituição que foram tratadas, num extenso documento assinado pela rede da Campanha Nacional pelo Direito à Educação e outras associações (ZINET, 2015) - contrárias à militarização das escolas, assim

\footnotetext{
${ }^{1}$ Além das manifestações de rua e em várias redes sociais, há notícias veiculadas de que o Exército brasileiro vem registrando pedidos de intervenção militar - da sociedade civil e de membros da corporação - não apenas nas escolas. Importante salientar a aprovação desses apelos conservadores também por uma parte dos docentes, tendo como exemplo o Movimento Docentes pela Liberdade, DPL (consultar site do grupo com mesmo nome).
} 
como privatização e cortes no orçamento -, e entregue ao Comitê dos Direitos da Criança da Organização das Nações Unidas (ONU). Como também demonstrava o documento, no tocante ao direito à educação, havia flagrante descumprimento do artigo 206 da Constituição da "liberdade de aprender, ensinar, pesquisar e divulgar o pensamento, a arte e o saber", do "pluralismo de ideias e de concepções pedagógicas" e da gestão democrática do ensino público. Santos (apud BARROSO, 2018) também lembra que o Art. 15 da Lei de Diretrizes e Bases da Educação regulamenta a prerrogativa de autonomia das escolas, progressivamente assegurada, o que é o oposto da intervenção de militares na gestão escolar. Do mesmo modo, os objetivos e propósitos das Diretrizes Curriculares Nacionais da Educação Básica não preconizam o princípio pedagógico dessas escolas, definido como "hierarquia e disciplina". Em relação aos profissionais do magistério, a militarização viola o art. 61 da LDB, que delimita que estão legalmente autorizados ao trabalho no ensino os professores e os trabalhadores da educação com habilitação específica, como destaca a matéria em questão.

Contudo, no início do mês de julho de 2019, rapidamente o governo tratou de aprovar uma Emenda Constitucional, EC 101/2019 (BRASIL, 2019b) que permite, conforme reiterado pelo site do Senado, que os policiais e bombeiros militares dos estados e do Distrito Federal possam acumular a função militar com cargos públicos nas áreas de saúde e educação (MAGELA, 2019), sem nenhum outro critério formativo ou seletivo. Em suma, o que até há pouco era evidentemente inconstitucional, passa a valer com a referida emenda, sem praticamente nenhum espanto da população, diante da manobra legal realizada. Como se observa, sem dúvida, a militarização das escolas públicas viola ainda - mesmo que com a aprovação da EC - a autonomia escolar e também os tratados internacionais assinados pelo Brasil (BARROSO, 2018) $)^{2}$, diante da questão da formação para o convívio social fundado na alteridade que nos constitui como humanos (não como intolerantes bárbaros!). Como define Catarina de Almeida Santos (apud CAMARGO, 2019), "A lógica da polícia é o controle, a força, e a lógica da escola tem que ser de liberdade, privilegiando o processo de aprendizagem", em entrevista para a Rádio Brasil Atual. Como também destaca, "o ensino militarizado impede o respeito às diferenças e é um formatador de mentes à medida que não dá conta de uma formação voltada à cultura e à cidadania”. Neste sentido, o sociólogo Manuel Castells, em entrevista recente no Brasil,

${ }^{2}$ Também não mantém diálogo com a sociedade, apresenta a possibilidade de abertura de privilégios em relação à reserva de vagas para dependentes de militares, a possível cobrança de taxas nas escolas que deveriam ser gratuitas, entre outras. 
reportada por vários jornais, explicita a obviedade do problema: "Não se pode fazer uma ditadura antiga, que se imponha com o exército, mas uma ditadura Orwelliana, de ocupar as mentes [...]" (FERREIRA, 2019).

No trajeto formativo mencionado (tanto no que se refere à universidade como às escolas participantes), cumpre destacar as influências do projeto Escola sem Partido (já incorporado nas mentalidades de muitos, ainda que não seja lei, de fato: suas ideias movimentam a Emenda Constitucional acima, por exemplo), como partes de uma mesma agenda/ intencionalidade tida como "reformista". Tal proposta - evidentemente "ideológica", ainda que não se defina ou assuma deste modo - busca censurar e punir os atores da escola, destacadamente os professores com suas "ideologias", a partir do que nomeiam como "doutrinação" das crianças e jovens. Em suas próprias palavras, "estudantes e pais preocupados" buscam combater o que concebem como: “contaminação político-ideológica das escolas brasileiras, em todos os níveis: do ensino básico ao superior", o que seria empreendido e personificado por "um exército organizado de militantes travestidos de professores" (NAGIB, 2019). Nessa nova espécie de cruzada moral e política (ou de caça-às-bruxas pós-moderna), Penna (2018) argumenta sobre a precariedade da situação dos professores perseguidos nessas investidas: "A pior consequência do discurso reacionário no campo educacional é a adesão de muitos à campanha de ódio aos professores, que leva a práticas persecutórias e ao denuncismo [...]" (p. 112).

Muitos outros movimentos, nessa direção repressiva, poderiam ser citados, como a extinção do Comitê contra a tortura (MELO; PRAZERES, 2019), extinção do Conselho Nacional dos Direitos da Pessoa com Deficiência (Conade), do Conselho Nacional do Meio Ambiente (Conama), do Fórum Brasileiro de Mudanças Climáticas e do Conselho Nacional de Combate à Discriminação de LGBTs, entre outros, através do Decreto 9.759/2019 (BRASIL, 2019a). Há ainda a proposta de exclusão do título de Patrono da Educação para Paulo Freire (RUDY, 2017) que continua em discussão e, de forma recorrente, surge nos discursos cotidianos contra as agendas progressistas, a partir da afirmação de que o educador foi um dos principais “doutrinadores de esquerda" e que continua a provocar a baixa na qualidade do ensino. Daí, aliás, a rápida efetivação do projeto de militarização das escolas que já estava em curso no país, em anos recentes.

Em profundidade, nesse cenário, há variáveis bastante reacionárias, além dos conhecidos motivos empresariais e neoliberais (CATINI, 2019; KRAWCZYK, 2018). Referimo-nos, nesse 
bojo, às "[...] formas contemporâneas que subjugam a vida ao poder da morte (necropolítica) ", uma "experiência demolidora da alteridade", como nomeou Hannah Arendt (MBEMBE, 2019, p. 18). Um modo de governo que concebe uma educação que naturaliza a morte ou outro tipo de violência (inclusive simbólica) para com "o outro", "o diferente", através da criação do inimigo, das máquinas de guerra pelo Estado (MBEMBE, 2019, p. 55).

Há várias denúncias de abusos físicos e psicológicos na formação de policiais militares no país (BARROS, 2015), como vem sendo noticiado frequentemente pela mídia, sem nos determos muito aqui aos casos de violência policial, bastante conhecidos da população mais vulnerável e dos cidadãos atentos ao entorno. Nesse âmbito, exemplos recentes, como o caso de "contenção física" de um professor em colégio militar no Amazonas, até com arma apontada para a cabeça e tapa no rosto, que declara após o processo de sofrimento físico e psicológico: "Emagreci 10 quilos, desenvolvi síndrome do pânico, sofro de insônia. Estamos mexendo com o alto escalão da polícia, é impossível não ter medo" (BASÍLIO, 2019). Ou ainda o caso da "revista" feita por militares, em escola cívico-militar de Goiânia, em adolescente arbitrariamente desnudados, com aparente anuência da direção da escola, não têm causado grandes impactos à população brasileira, convencida de que a "disciplina" e uso de força fazem-se necessárias como "ferramentas corretivas/pedagógicas" para uma sociedade melhorada.

Com base nessa acepção, destacamos tais práticas como afeitas às necropolíticas, concebendo tais investidas como reconfigurações/ atualizações nos dispositivos de biopoder, a partir da acepção foucaultiana. Recentemente, por exemplo, o Exército Brasileiro publicou uma nota em seu site oficial, em homenagem a um major alemão, Otto von Westernhagen, condecorado por Hitler (GUERRA; CAMPOS, 2019).

Diniz e Carino (2019), discutindo a situação do Brasil e de alguns países da América Latina, completam: "Quando o funcionamento do Estado escancara a necropolítica como regime de governo das populações, passamos a descrever a desordem como "emergência", "conflito armado" ou "crise humanitária". Nessa perspectiva, não causou tanto espanto à população a frase pronunciada pelo então candidato à vice-presidência do Brasil, General Hamilton Mourão, quando do atentado ao candidato à presidência, Jair Bolsonaro: "Se querem usar a violência, os profissionais da violência somos nós", como divulgou o jornal El País (BRUM, 2018).

Toda essa sustentação e proliferação de uma "cultura da violência", portanto, circula também pelas escolas e em suas relações, evidentemente, intensificada agora diante do problema 
em torno da posse e porte de armas, difundido como alternativa de "defesa pessoal" do cidadão, em andamento no país (contrariando inúmeras pesquisas de âmbito não apenas nacional e alertas feitos pela Anistia Internacional, por exemplo), dentre outros fatores (BARBIÉRI, 2019). É justamente contra tais aspectos, que nos apoiamos nos preceitos freireanos que concebem a prática pedagógica como libertadora (o oposto do que seria uma educação policialesca), para muito além de uma questão metodológica, tendo as diferenças como centralidade de uma pedagogia que prioriza radicalmente a efetivação dos direitos humanos, isto é, para muito além da letra da lei.

Assim, medo/ angústia e ousadia, (im) possibilidades curriculares - nas práticas e concepções pedagógicas - foram considerados e discutidos nas propostas de formação docente em torno das diferenças e sua potência, criadas em grupos temáticos (com cerca de 4 a 6 membros), nos encontros na universidade e nas análises mais particulares dos estudantes, a partir de processos formativos de estágio, comentados a seguir.

\section{Os sentidos produzidos a partir de prática pedagógica centrada nas diferenças: um caso de formação docente ${ }^{3}$}

É sabido que a escola é um dos primeiros palcos de encontro com a diferença e, mais do que isso, com a desigualdade. É no espaço escolar em que há os primeiros momentos de constatação de relações sociais e que se experimentam as primeiras linhas da malha do poder, para emprestar a expressão foucaultiana. O presente relato se propõe a refletir acerca das questões conceituais de diferença e desigualdade, com vistas a também pensar os processos pelos quais os sentidos desses conceitos são produzidos pelos/as alunos/as em articulação com suas experiências de ser/estar no mundo.

As reflexões aqui apresentadas foram feitas a partir de um estágio que visava ao acompanhamento das aulas de Sociologia ministradas ao Ensino Médio de uma escola de período integral de Campinas/SP. Ali, o PEI - Projeto de Escola Integral (SÃO PAULO, 2013) mostra-se central para a constituição de uma espécie de identidade escolar que, de certa maneira, orienta as formas pelas quais alunos e docentes experienciam sua passagem pela escola, como observado.

\footnotetext{
${ }^{3}$ A fim de preservar a identidade dos (as) estudantes e da professora, resolvemos suprimir seus nomes, bem como o nome da escola.
} 
Também era objetivo do estágio propor e realizar uma intervenção que tratasse sobre o tema da diferença, como já mencionado.

Quanto à proposta de intervenção do referido estágio, cumpre destacar que, durante o período de acompanhamento das aulas, os temas tratados giraram principalmente em torno dos assuntos "Movimentos Sociais", "Mundo do Trabalho" e "Violências". Foi claro o intuito da professora em relacionar esses assuntos aos acontecimentos correntes e às notícias sobre o cenário político brasileiro. Também foram realizados debates e exposições sobre a formação do povo brasileiro, bem como sua diversidade étnica e cultural.

A tônica das aulas foi refletir sobre as maneiras pelas quais tratamos a diferença em períodos de acirramento político e intolerância. Nesse sentido, um ponto de destaque foi o debate sobre atos xenofóbicos ocorridos à época e se o Brasil é ou não hostil com refugiados (MENDONÇA, 2018; RAMALHO, 2019). Os jovens estudantes construíram uma argumentação que, em um primeiro momento, focava na concepção de que o Brasil não era xenófobo. Logo, outros(as) estudantes se opuseram, lembrando diversos casos de racismo que aparecem na mídia e sua consequente naturalização. A argumentação final dos estudantes apontou que o país não é hostil ou preconceituoso com todos os imigrantes ou refugiados, mas apenas com aqueles que carregam marcadores sociais da diferença que são marginalizados, no seio da própria sociedade brasileira, como a população negra e LGBTQI, por exemplo. Dessa maneira, eles e elas discutiram acerca das diversas linhas de força que constroem nossa sociedade, linhas essas que, por sua vez, foram constituídas por diversos processos históricos que formaram nossa nação (LIMA, 2018) $)^{4}$.

A proposta era discutir como se formavam as noções de diferença e desigualdades, tendo em mente seu caráter circunstancial a um período no espaço-tempo. Pretendia-se provocar as/os jovens estudantes a desnaturalizar a diferença e enxergá-la como imanente à vida humana. A partir disso, pensar como as diferenças se tornam desigualdades, através de processos históricos que se inscrevem no corpo e na vida cotidiana de muitas pessoas. Também era intenção da aula mostrar redutos de resistência a essas desigualdades que marginalizam corpos e desautorizam existências.

\footnotetext{
${ }^{4}$ A autora argumenta ser a presença tácita da escravidão (enquanto moduladora de relações sociais) no imaginário social brasileiro uma das linhas de força mais potentes na constituição da nossa nação. A partir dela pode se estabelecer uma chave de análise a fim de entender aquilo que ela caracteriza como "necropolítica à brasileira" , isto é, a lógica que (in)forma ações (inclusive estatais) acerca de quem pode morrer e quem deve viver. Em outras palavras, quais corpos são passíveis de luto (grievable) - adotando o léxico butleriano - e quais não.
} 
A intervenção/aula tinha como foco de especial cuidado a noção de violência simbólica, posto que os estudantes tiveram dificuldade com o domínio desse conceito. Para tanto, foram usados dois vídeos para provocar o debate acerca de violência simbólica. O primeiro, da série apresentada pela Netflix, intitulado Explained (POSNER; KLEIN, 2018), com episódio chamado "A diferença da riqueza entre negros e brancos nos EUA" (The Racial Wealth Gap). O segundo é um vídeo intitulado O Mito de Bolsonaro: o que pensam e como se organizam seus apoiadores? (VICE BRASIL, 2018). Nele é possível ver cenas do protesto do grupo "Direita-SP”, na porta do Sesc Pompeia, contra a presença de Judith Butler e sua dita "ideologia de gênero", infeliz e erroneamente também caracterizada por um dos manifestantes como "erotização de nossas crianças". Trechos de ambos os vídeos foram exibidos e posteriormente discutidos, atentando-nos à relação entre a primeira parte da aula, mais expositiva, e uma possível "aplicação" para as cenas que estavam sendo mostradas nos vídeos.

A exibição dos vídeos gerou debates acalorados sobre os tratamentos da diferença. De maneira geral, o vídeo sobre as eleições suscitou mais reações por parte dos jovens da sala. Alguns deles não se sentiram tímidos em enunciar suas opiniões, dizendo que aquele documentário tinha sido produzido por apoiadores do Partido dos Trabalhadores (PT) e feito com o propósito de impedir a vitória de Bolsonaro nas eleições. Esse argumento levou a uma acirrada reação de outra parcela dos estudantes que não se identificava com as opiniões reconhecidamente truculentas do futuro presidente.

Alguns estudantes se posicionaram enquanto integrantes da comunidade LGBTQI e se apropriaram das ferramentas de análise discutidas ali para pensar suas próprias formas de ser e estar no mundo, de uma maneira crítica, em face aos novos desafios. Argumentaram que a presença das opiniões excludentes emitidas por Bolsonaro e seus eleitores eram um ensejo para o surgimento de focos de legitimação de violências também simbólicas que, rapidamente, se desdobrariam em episódios de violência física. Ao que responderam os primeiros ser mais um episódio da tendência de "mimimi" que os "petistas" teriam.

Em um momento marcante, alguns estudantes compartilharam suas experiências de tomada de consciência de que seus corpos eram considerados diferentes. Eles e elas relataram episódios de racismo, homofobia e lesbofobia e, à medida que falavam, construíam cada vez mais explícita a noção de que a diferença é, na maioria das vezes, tratada como sinônimo de desigualdade em vez de diversidade. Chegamos juntos à conclusão de que, com base na 
diferença, se articula um conjunto muito vasto de práticas de violência simbólica; seja um olhar, uma recusa, um desconforto; todas essas são táticas sutis (mas não por isso menos complexas) de marginalização dos corpos "diferentes".

Após isso, juntos refletimos sobre a invisibilidade da norma que se dá através de um processo de naturalização que, por exemplo, atribui raça apenas aos corpos negros, gênero apenas às mulheres (cis ou trans) e classe apenas aos pobres. Um aluno, cujos pais são nordestinos, fez uma metáfora muito cabível para esse processo, argumentando: “quando conhecemos alguém de outro lugar, achamos que só ele tem sotaque e que nós não temos”. Em outras palavras, a diferença apenas se dá naqueles sujeitos que diferem do cidadão "ideal” naturalizado, basicamente: um homem cisgênero branco, cristão, classe média, heterossexual e urbano.

Para além da sala de aula, a partir da intervenção e do tempo passado na escola - tendo em mente as recomendações de Fernando Seffner (2013) - é impossível contornar a ideia de que é necessária uma mudança nos termos da discussão sobre os sentidos da diferença. Há uma tendência perpetrada tanto pela academia quanto pela sociedade abrangente em pensar a diferença enquanto uma insígnia ou um estigma ${ }^{5}$ que são usados por determinados sujeitos.

Assim, promove-se a manutenção dos mecanismos que naturalizam a desigualdade, colocando-a na esteira da diferença.

\section{Formação docente no campo de Língua Portuguesa na Educação Básica: intervenções com foco nas diferenças}

A partir de um estágio realizado em uma escola pública de uma cidade da região metropolitana de Campinas-SP, acompanhando a disciplina de Língua Portuguesa, no contexto do segundo ciclo do ensino fundamental, foi possível mobilizar as reflexões e considerações aqui apresentadas. Orientando o olhar para a questão da diferença, o período passado na escola permitiu, num momento de formação docente, tomar a dimensão da alteridade como constitutiva do cotidiano escolar e também (re) produtora de afetividades.

A aproximação com a escola se deu de maneira orgânica e proveitosa. Já na primeira visita foi possível conversar com a professora supervisora, Amanda ${ }^{6}$, e com a diretora, que foram muito receptivas em relação à nossa presença. Com a professora Amanda, inclusive, houve

\footnotetext{
${ }^{5}$ Aludimos ao sentido original do termo stigma em grego, que se refere a uma marca ou sinal natural do corpo.

${ }^{6}$ Nome fictício, para preservar identidade dos participantes do estágio de formação docente.
} 
conversas de corredor e de intervalo que nos ajudaram a compreender o ambiente escolar de estágio e conversar sobre o cotidiano docente naquele espaço.

Observamos, no período estagiado que, onde os estudantes do $1^{\circ}$ ano têm entre 14 ou 15 anos, os alunos de 17 tendiam a chamar atenção, em especial pelo total descaso com a instituição escolar e falta de propósito ainda mais aparente (muitos, aliás, são encaminhados à EJA).

Foram observadas três turmas nos meses de estágio e cada uma mostrou, aos poucos, seus protagonistas e suas dinâmicas próprias. Foi possível perceber que há, também pelo fato de ser uma cidade pequena - onde quase todos frequentam os mesmos espaços e as famílias são conhecidas umas das outras - um sentimento de comunidade, mas não de pertencimento ao espaço escolar. Ainda que uma sala tivesse um grupo de alunos mais engajado, falante e participativo - e as outras duas salas demonstrassem mais apatia - foi recorrente ver estudantes ao fundo, ouvindo música, lendo, mexendo no celular ou apenas copiando a matéria da lousa, por se sentirem obrigados, ou copiando exercícios de colegas porque há a "ameaça" de que o comportamento, mais ou menos adequado, seria refletido na nota final do bimestre.

Em uma escola de relativa boa estrutura e com espaços agradáveis de convivência é de se pensar quais elementos, endógenos e exógenos, estariam afetando ${ }^{7}$ adolescentes negativamente e produzindo as desmotivações aparentes (ALMEIDA; MAHONEY, 2007, LEME; OLIVEIRA, 2011).

Tendo em vista o olhar sobre a diferença e como ela é significada (ou se há espaço simbólico para ela) na escola, a questão da motivação se apresentou como algo interessante a se considerar, isto é, poder ouvir os jovens sobre o que circula socialmente: que eles não querem saber de nada ou eles são preguiçosos. Do mesmo modo, atentar para o fato de que é aparente, em muitos professores, uma desmotivação e um adoecimento da categoria. Nesse sentido, o olhar foi direcionado para quais, potencialmente, poderiam ser os elementos (des) motivadores. Para tanto, após os debates e leituras discutidas em grupo, na universidade, buscou-se compreender a circulação de afetos nas relações entre professores e jovens estudantes, assim como os processos de in/exclusão relacionados às (des) motivações, como a via teórica para refletir sobre a motivação desses jovens na escola estagiada.

7 Em relação ao conceito de afecção, para compreendermos as (des) motivações humanas, apoiamo-nos no referencial teórico histórico-cultural. Isso significa assumir as (des) motivações como produzidas (também) do ponto de vista sócio histórico, dadas as relações concretas entre os seres humanos e o mundo. 
Como sintetiza Sawaia (2003), ao tomar o sofrimento ético-político como categoria de análise e considerar os afetos no desenvolvimento humano, buscamos olhar a escola, como instituição social e política, que via de regra culpabiliza os indivíduos pelo fracasso (tanto alunos quanto professores) e se ausenta de debates importantes como racismo, LGBT fobia, machismo, monolinguismo e, nesse movimento, nega simbolicamente a diferença e o sofrimento éticopolítico. Assim, é bastante importante considerar a desmotivação como sofrimento do indivíduo que, no limite, recusa a existência. Isso significa deslocar o indivíduo da posição de culpado e buscar ouvir o que, afinal, faz ou não sentido para ele, na/ sobre a escola. Foi, portanto, nessa direção que a intervenção foi concebida e desenvolvida.

As aulas da professora Amanda acompanhadas foram em sua maioria de Gramática e algumas de Literatura. A falta de organicidade no ensino dessas "frentes" e a divisão do saber linguístico, que por sua vez está ainda muito atrelado ao conhecimento delimitado em tecnologias como gramáticas e dicionários, parece já ser algo recorrente como mecanismo desmotivador.

A professora Amanda mantinha uma relação próxima com os alunos e de respeito mútuo. Novamente a questão da cidade pequena merece destaque, pois a professora frequenta vários dos espaços que as famílias dos estudantes frequentam, encontra com os pais no dia-a-dia fora da escola e isso também contribui para o reconhecimento da professora como referência. Os gritos, que possivelmente afetam negativamente muitos alunos, se mostraram uma estratégia disciplinadora por parte da professora, que alguns jovens inclusive aprovam (alguns disseram: "é bom professor que consegue controlar a sala porque tem gente aqui que quer aprender”). Outra questão que surgiu das aulas observadas foi o fato de o estágio ter sido realizado majoritariamente às sextas-feiras; muitos alunos (assim como professores) já estavam cansados e, nesse mesmo dia, aconteciam as aulas de Educação Física. Os estudantes esperavam ansiosamente durante as aulas de Português.

Não pareceu haver uma dificuldade nos processos de alfabetização e letramento por grande parte dos estudantes nas aulas de Língua Portuguesa. Entretanto, a aprendizagem sem significado (ainda que houvesse diversas tentativas da professora de aproximação do conteúdo ao cotidiano dos alunos) e sem relação com o cotidiano desses jovens parecia ser a real engrenagem para a desmotivação: afinal, a organização de escola se mostrava pautada nos moldes do séc. XIX, com o qual eles não se identificavam, obviamente. Nesta direção, somava-se o fato de não 
"serem ouvidos" ou "valorizados", como observado. Em última análise, pareciam se perguntar: "mas pra quê eu vou usar isso na vida?"

Neste contexto, a primeira parte da intervenção foi realizada num dia, logo no início de cada aula. Foram distribuídas folhas em branco, sem limitação de espaço e a pergunta "O que há de bom e o que há de ruim na escola?" foi escrita na lousa, para os estudantes que se sentissem confortáveis em participar, sem necessidade de identificação.

As jovens, em especial, pareceram mais à vontade para escrever; faziam com capricho e perguntavam se podiam escrever mais. Dentre os que escreveram pouco (em sua maioria rapazes), falavam que "de bom tem os amigos e de ruim uns professores muito chatos". A maneira como alguns se ausentaram foi interessante: uma jovem esperou um momento em que achou que não era observada, para esconder a folha na bolsa, como se fosse proibido não resolver a atividade, e um rapaz olhou para os colegas e perguntou o que eles colocaram para copiar, mas no fim dobrou a folha e deixou embaixo da mesa. Muitos se preocuparam com as regras: se podia fazer à caneta ou de lápis, se precisava colocar nome, se tinha que ser texto ou poderia ser tópico... A liberdade com elementos tão simples parece incomodar, mesmo sendo uma sala de $1^{\circ}$ ano de E.M.

Em relação à motivação, as respostas coletadas foram surpreendentes (dada sua aparente simplicidade), do nosso ponto de vista, em relação ao que os alunos gostam: passeios, teatro e filmes. O respeito e os "professores amigos" são muito mais citados, em relação à estrutura escolar ou a falta de dinheiro. O que "há de bom" parece estar muito mais no campo do vir a ser, do futuro, de algo que ainda vai ser importante. Já o que "há de ruim” é muito perceptível para eles, a partir da análise desses relatos (como disseram: "tem alunos que atrapalham, tem professores que não são muito respeitosos, não pode fazer nada que já ligam pra mãe...”). Nesse sentido há, como propõe Sawaia (2003) uma consideração supérflua da cultura e do lazer aos marginalizados, como se a eles isso não fosse digno.

A segunda parte da intervenção envolveu um retorno à escola, do que pôde ser observado nos relatos dos estudantes, em relação à circulação de afetos presente no espaço. A elaboração de uma carta foi pensada como uma maneira de devolver algo à escola, considerando o que foi produzido por nossos olhares, quando da intervenção. Muitas vezes, no cotidiano acelerado, muitos professores e a coordenação reproduzem mecanismos de homogeneização e colonização 
de corpos que, ao invés de produzirem efeitos desejados ou um ambiente de convivência agradável, acabam por gerar desmotivações, descréditos ou a temida rebeldia.

\section{Ao que nos lança a discussão em torno da mesmidade e da diferença nas escolas?}

Tratando a diferença enquanto algo reificado, acaba-se por transformá-la em objeto exótico sempre passível do escrutínio da norma. Seffner (2013) observa que são sempre os "diferentes" que são convocados a falar de si. Foi explicitamente o que percebemos durante o debate aqui relatado, nas aulas de Sociologia, quando os/as alunos/as começaram a falar da constatação da diferença percebida e atribuída a seus corpos e foram crescentemente instados a falar disso, numa espécie de relato de si que examinava e circunscrevia a forma mesma dessa diferença. A astúcia dos "normais" é de invisibilizar seus corpos enquanto atravessados por esses mesmos marcadores, atribuindo a si mesmos o verniz de uma espécie de naturalidade essencial.

Assim, vale novamente salientar que as escolas precisam avançar sobre as diferenças em termos de diversidade/ pluralidade a serem respeitadas (o que se configura, quase sempre, numa individualização do desvio em relação à norma/ ao "normal" e se coloca numa proposta assimilacionista e/ou colaborativa, a partir de uma lógica liberal de reconhecimento), como nos adverte Frangella (2018). Como a autora também salienta, tal perspectiva hierarquiza e não problematiza, de fato. Apenas normaliza a diferença e não apresenta um caráter hibridizador amplo nessa seara, nas palavras de Bhabba (2011 apud FRANGELLA, 2018), pois mantém posições binárias nós/eles, dentro/ fora, "sem perturbar uma pretensa horizontalidade de uma perspectiva liberal democrática" (FRANGELLA, 2018, p. 184).

Também enfatizamos que é impossível contornar a ideia da magnitude da potência da sala de aula (suas brechas/ aberturas). Neste sentido, Macedo (2017) argumenta que os ataques feitos à noção da diferença no que tange gênero e sexualidade na Base Nacional Comum Curricular, BNCC, e que foram fomentados pelo Escola Sem Partido, são muito poderosos e decisivos, mas que não preveem o controle da possibilidade da ação docente dentro de uma sala de aula. Essa variável é difícil de ser controlada, segundo a autora, com a qual concordamos. Com base na experiência em questão, no Ensino Médio, em ambas os casos, essa assertiva se mostrou possível.

É evidente que os docentes obedecem a diversas instâncias e amarras, sejam elas gestadas na escola ou fora dela. Entretanto, o que se argumenta é que ninguém pode prever os fluxos e forças 
dos acontecimentos, diante do debate dentro das quatro paredes de uma sala de aula (nem mesmo o docente), a despeito dos riscos iminentes.

Neste contexto, destacamos a importância de insistirmos nas temáticas em torno de questões de interseccionalidade: noções de classe, raça/etnia e gênero (isto é, sobre o capitalismo, o colonialismo e o patriarcado, destacados por Santos e Martins (2019), como a tríade responsável pela criação sistemática de injustiças e opressões sociais, culturais e subjetivas, além das questões geracionais (SARMENTO, 2005) em que se destacam os processos adultocêntricos de repressão e governamento das crianças e adolescentes.

Finalmente, cumpre considerar que o exercício de (re)centralizar nossa formação docente, a partir da Pedagogia da Diferença, permite uma importante reflexão sobre como a criação de um ambiente que gera afetos positivos - no qual todos se sintam acolhidos, respeitados, pertencentes e valorizados - torna-se uma potencialidade para microagências e micropolíticas no ensinoaprendizagem. Na contramão dessa reflexão, pudemos perceber como o movimento de homogeneização dos estudantes ocorre, no caso das aulas de Português relatadas - e que estar na posição de liderança de uma classe desmotivada é tarefa extremamente desafiadora.

Nesse ínterim, há, como apontam Skliar e Souza (2007), esse caráter implícito da norma que a torna invisível e inquestionável e, assim, a diversidade é apagada, bem como a alteridade e suas especificidades, discursos e lutas políticas, ideológicas (coletivas e subjetivas). Como observado, foi possível verificar como a (des)motivação, intrinsecamente relacionada à produção da exclusão social, mostrou-se vinculada a um ambiente que não prioriza a assunção plena da alteridade, ainda que o discurso do "aceitável mesmo que diferente" esteja presente, silenciando e apagando as singularidades, pluralidades e as diferenças (isso para refletirmos - em termos de mesmidade ou alteridade - o que é/ seria a realidade de uma escola militarizada, quando até as vestimentas, cortes de cabelo e palavreado dos jovens são controlados e decididos por outrem).

Diante de todos os enormes entraves sociais/culturais, políticos e econômicos, a que as universidades e escolas públicas estão submetidas (quase aterradas!), como nos lembram Zan e Mazza (2018), devemos nos defender “[...] na coragem de ir a público defender a democracia por meio de uma atitude ativa, comprometida e qualificada" (p. 202). É preciso ousar em retomar a história de desigualdade no país - desde os tempos coloniais até os modos atualizados de escravização humana - quando as ações populistas insistem em falsear fatos que seriam facilmente comprovados. Nas palavras de Schwarcz, "Tais momentos costumam desaguar em 
disputas pela melhor versão do passado. Nessa hora, a história se transforma numa sorte de justificativa, enredo e canto de torcida organizada" (2019, p. 21).

Assim, à educação caberá enfrentar - talvez como nunca - o totalitarismo que se anuncia em nosso tecido social, o que também parece ser o "antídoto" defendido por Castells, na entrevista recente mencionada acima (FERREIRA, 2019). Com esse propósito de combate aos modos autoritários e de extermínio da diferença/ "do diferente", em que o medo e o pânico são os motores para um pensamento raso e simplista da sociedade, a educação libertária e a educação para os direitos humanos têm um papel fundamental, uma vez que assumem a pluralidade das existências e dos modos de vida como centralidade. Neste contexto, as práticas e estágios supervisionados na formação docente - em torno das diferenças como elemento fundante do currículo da Educação Básica - tornam-se urgentes, quando também priorizam modos (cri) ativos de participação dos futuros professores que, consequentemente, podem buscar pelas reverberações desses desejos de uma escola outra, quando dos encontros com os participantes nos campos de estágio. Podem vislumbrar - portanto afetados e encorajados pelo conjunto de devires - a educação como um tipo de indisciplina e de exposição numa postura experimental (MASSCHELEIN; SIMONS, 2014). Podem ter no horizonte as possibilidades de uma sociedade mais justa e consciente dos equívocos fomentados, permitidos e perpetrados por diversas formas de poder e controle, até aqui, sobre os distintos modos de existência, de subjetividades e seus fluxos. Podem viver uma experiência de educação, portanto, contra a morte e a mortificação dos corpos e mentes, o medo, a impotência e o terror que a mesmidade/normalidade engendra/ camufla/ evoca/ grita/ legisla/ impõe (notadamente em tempos difíceis, quando se vale de muitas máscaras e artimanhas escorregadias - a maioria, aliás, valendo-se do clamor pela "democracia" e pelos "direitos humanos"). Uma luta dos educadores, portanto, contra o medo, a violência, a ignorância, o totalitarismo, a necropolítica (MBEMBE, 2019) ramificada nas escolas e em seus arredores e que (re)instaura guerras cotidianas, sob o manto da necessidade.

\section{Referências}

ALMEIDA, Laurinda Ramalho; MAHONEY, Abigail Alvarenga (org). Afetividade e aprendizagem: contribuições de Henri Wallon. São Paulo: Edições Loyola, 2007.

BARBIÉRI, Luiz Felipe. Anistia Internacional recomenda revogação do decreto das armas. G1 Politica, Brasília, 21 maio 2019. Disponível em: https://g1.globo.com/politica/noticia/2019/05/21/anistiainternacional-pede-revogacao-de-decreto-das-armas.ghtml. Acesso em; 26 jul. 2019. 
LINS, Heloisa Andreia de Matos; MARQUES, Gabriela Antunes; RAGNANE, Homero Dantas. Pedagogia das diferenças e a formação docente em tempos de necropolíticas.

BARROS, Ciro. Formação da PM é baseada em abusos, dizem policiais. Revista Exame, Brasil, 24 jun. 2015. Disponível em: https://exame.com/brasil/formacao-da-pm-e-baseada-em-abusos-dizem-policiais/. Acesso em: 1 jul. 2019.

BARROSO, José de Ribamar Virgolino. Militarização do ensino fere a Constituição. Carta Capital, Brasil, 18 set. 2018. Disponível em: https://www.cartacapital.com.br/opiniao/militarizacao-do-ensinofere-a-constituicao/. Acesso em: 22 jan. 2019.

BASÍLIO, Ana Luiza. "É impossível não ter medo", diz professor agredido em colégio militar no Amazonas. Carta Capital, Brasil, 22 out. 2019. Disponível em:

https://www.cartacapital.com.br/educacao/e-impossivel-nao-ter-medo-diz-professor-agredido-em-colegiomilitar-no-amazonas/. Acesso em: 26 out. 2019.

BRASIL. Presidência da República. Decreto No 9.759, de 11 de abril de 2019. Extingue e estabelece diretrizes, regras e limitações para colegiados da administração pública federal. Brasília: Presidência da República, 2019a. Disponível em: http://www.planalto.gov.br/ccivil_03/_ato2019 2022/2019/Decreto/D9759.htm. Acesso em: 4 jul. 2019.

BRASIL. Presidência da República. Emenda Constitucional No 101, de 3 de julho de 2019. Acrescenta $\S 3^{\circ}$ ao art. 42 da Constituição Federal para estender aos militares dos Estados, do Distrito Federal e dos Territórios o direito à acumulação de cargos públicos prevista no art. 37, inciso XVI. Brasília: Presidência da República, 2019b. Disponível em:

https://presrepublica.jusbrasil.com.br/legislacao/728405973/emenda-constitucional-101-19. Acesso em: 12 jul. 2019.

BRUM, Eliane. Profissionais da violência. A reação de Mourão, o vice 'faca na caveira' de Bolsonaro, aponta como o Brasil será governado em caso de vitória da chapa de extrema direita. El País, Madri, 11 set. 2018. Disponível em: https://brasil.elpais.com/brasil/2018/09/10/opinion/1536582945_652291.html. Acesso em: 2 fev. 2019.

CAMARGO, Marcelo. MEC deve ampliar número de escolas militarizadas no Brasil. Rede Brasil Atual, São Paulo, 12 fev. 2019. Disponível em: https://www.redebrasilatual.com.br/educacao/2019/02/mec-deveampliar-escolas-militarizadas-criticadas-por-ferir-parametros-educacionais/. Acesso em: 4 jul. 2019.

CÁSSIO, Fernando (org). Educação contra a barbárie: por escolas democráticas e pela liberdade de ensinar. São Paulo: Boitempo, 2019.

CATINI, Carolina. Educação e empreendedorismo da barbárie. In: CASSIO, F. (org). Educação contra a barbárie: por escolas democráticas e pela liberdade de ensinar. São Paulo: Boitempo, 2019. p. 33-40.

DINIZ, Débora; CARINO, Giselle. A necropolítica como regime de governo: o próprio funcionamento dos Estados da América Latina promove em muitas ocasiões políticas da morte. El País, Madri, 16 jul. 2019. Disponível em: https://brasil.elpais.com/brasil/2019/07/09/opinion/1562688743_395031.html. Acesso em: 17 jul. 2019.

FERREIRA, Paula. 'VOCÊS estão vivendo um novo tipo de ditadura', diz sociólogo Manuel Castells. O Globo, Rio de Janeiro, 17 jul. 2019 Disponível em: https://oglobo.globo.com/sociedade/voces-estaovivendo-um-novo-tipo-de-ditadura-diz-sociologo-manuel-castells-23812733. Acesso em: 17 jul. 2019.

FRANGELLA, Rita de Cássia Prazeres. Do silêncio e seus sons: "diferenças" na Base Nacional Comum Curricular. In: LOPES, Alice Casimiro; OLIVEIRA, Anna Luiza Araújo Ramos Martins de M.; OLIVEIRA, Gustavo Gilson Sousa de. Os gêneros na escola e o (im)possível silenciamento da diferença no currículo. Recife: Ed. UFPE, 2018. p. 163-186.

KRAWCZYK, Nora (org). Escola pública: tempos difíceis, mas não impossíveis. Campinas: FE/UNICAMP, 2018. Disponível em: 
LINS, Heloisa Andreia de Matos; MARQUES, Gabriela Antunes; RAGNANE, Homero Dantas. Pedagogia das diferenças e a formação docente em tempos de necropolíticas.

https://docs.wixstatic.com/ugd/35e7c6_b164114ceb7e443a929679a4b417d7b9.pdf. Acesso em: 12 jan. 2019.

LEME, Maria Isabel da Silva; OLIVEIRA, Paulo de Salles (org.). Proximidade e distanciamento: superando dicotomias. São Paulo: Casa do Psicólogo, 2011.

LIMA, Fátima. "Bio-necropolítica: diálogos entre Michel Foucault e Achille Mbembe. Arquivos Brasileiros de Psicologia, Rio de Janeiro, v. 70, n. especial, p. 20-33, 2018.

MACEDO, Elizabeth. As demandas conservadoras do movimento escola sem partido e a base nacional comum curricular. Educação e Sociedade, Campinas, v. 38, n. 139, p. 507-524, abr./jun. 2017.

MAGELA, Geraldo. Promulgada emenda que permite a militar acumular cargo em saúde e educação. Senadonotícias, Brasília, 3 jul. 2019. Disponível em: https://www12.senado.leg.br/noticias/materias/2019/07/03/promulgada-emenda-que-permite-a-militaracumular-cargo-em-saude-e-educacao. Acesso em: 12 jul. 2019.

MASSCHELEIN, Jan; SIMONS, Maarten. A pedagogia, a democracia, a escola. Belo Horizonte: Autêntica, 2014.

MELO, Igor; PRAZERES, Leandro. Bolsonaro exonera equipe de combate à tortura; órgão diz que vai recorrer. Notícias UOL, Rio de Janeiro, 11 jun. 2019. Disponível em:

https://noticias.uol.com.br/politica/ultimas-noticias/2019/06/11/bolsonaro-exonera-equipe-de-combate-atortura-orgao-diz-que-vai-recorrer.htm. Acesso em: 13 jun. 2019

MBEMBE, Achille. Necropolítica. São Paulo: n-1 edições, 2019.

MENDONÇA, Heloísa. O "monstro da xenofobia" ronda a porta de entrada de venezuelanos no Brasil. El País, Madri, 27 ago. 2018. https://brasil.elpais.com/brasil/2018/08/17/politica/1534459908 846691.html. Acesso em: 13 set. 2019.

GUERRA, João Paulo Diniz; CAMPOS, Renato Rocha Drubsky de. Tributo ao Major Eduard Ernest Thilo Otto Maximilian von Westernhagen, oficial alemão assassinado no Brasil por um ato terrorista em 1968. Brasília: Ministério da Defesa. Exército Brasileiro, 2019. https://www.eb.mil.br/web/noticias/fatos-historicos/-/asset_publisher/QKzf8DsobUm1/content/tributo-aomajor-eduard-ernest-thilo-otto-maximilian-von-westernhagen-oficial-alemao-assassinado-no-brasil-porum-ato-terrorista-em-1968._Acesso em: 26 fev. 2021.

MORETTI, Isabella. Militarização das escolas: entenda o que é e como funciona: unidades escolares comandadas pela PM defendem disciplina, civismo e patriotismo. Via Carreira, Brasil, 1 mar. 2019. Disponível em: https://viacarreira.com/militarizacao-das-escolas/. Acesso em: 12 jul. 2019.

NAGIB, Miguel. Escola sem partido. 2019. Disponível em: http://escolasempartido.org/. Acesso em: 25 fev. 2021.

PENNA, Fernando de Araújo. O discurso reacionário de defesa de uma "escola sem partido". In:

GALLEGO, Esther Solano (org.). O ódio como política: a reinvenção das direitas no Brasil. São Paulo: Boitempo, 2018. p. 109-113.

POSNER, Joe; KLEIN, Ezra. Explained: the racial wealth gap. Estados Unidos: Vox, Netflix, 2018. 1 vídeo (16 min). 2 temporadas, séries documentais. Disponível em: www.netflix.com. Acesso em: 25 set. 2018.

RAMALHO, Sérgio. Virou rotina agredir e assassinar venezuelanos em Roraima. The Intercept Brasil, Rio de Janeiro, 28 nov. 2019. Disponível em: https://theintercept.com/2019/11/28/violencia-xenofobiavenezuelanos-roraima/. Acesso em: 5 dez. 2019.

RICCI, Rudá. A militarização das escolas públicas. In: CÁSSIO, Fernando. (org). Educação contra a barbárie: por escolas democráticas e pela liberdade de ensinar. São Paulo: Boitempo, 2019. p. 107-114. 
RUDY, Jefferson. Sugestão que pede retirada de título de Paulo Freire é 'absurda', segundo convidados de audiência. Senadonotícias, Brasília, 28 nov. 2017. Disponível em:

https://www12.senado.leg.br/noticias/materias/2017/11/28/sugestao-que-pede-retirada-de-titulo-de-paulofreire-e-201cabsurda201d-segundo-convidados-de-audiencia. Acesso em: 26 fev. 2021.

SARMENTO, Manuel J. Gerações e alteridade: interrogações a partir da sociologia da infância. Educação e Sociedade, Campinas, v. 26, n. 91, p. 361-378, 2005.

SAWAIA, Bader Burihan. Fome de felicidade e liberdade. In: CENPEC. Muitos lugares para aprender. São Paulo: CENPEC / Fundação Itaú Social/Unicef , 2003. p. 53-64.

SANTOS, Boaventura de Sousa; MARTINS, Bruno Sena. Introdução: o pluriverso dos Direitos Humanos. In: SANTOS, Boaventura de Sousa; MARTINS, Bruno Sena (org). O pluriverso dos direitos humanos: a diversidade das lutas pela dignidade. Belo Horizonte: Autêntica, 2019. p. 13-36.

SÃO PAULO. Diretrizes do Programa Ensino Integral: Escola de Tempo Integral. São Paulo: SEE, 2013. Disponível em: https://www.educacao.sp.gov.br/a2sitebox/arquivos/documentos/342.pdf. Acesso em: 10 ago. 2018.

SEFFNER, Fernando. Sigam-me os bons: apuros e aflições nos enfrentamentos ao regime da heteronormatividade no espaço escolar. Educação e Pesquisa, São Paulo, v. 39, n. 1, p. 145-159, 2013.

SCHWARCZ, Lilia Moritz. Sobre o autoritarismo brasileiro. São Paulo: Companhia das Letras, 2019.

SKLIAR, Carlos. La pronunciación de la diferencia entre lo filosófico, lo pedagógico y lo literario. ProPosições, Campinas, v. 26, n. 1, p. 29-47, abr. 2015. Disponível em: https://www.scielo.br/scielo.php?pid=S0103-73072015000100029\&script=sci abstract\&tlng=es. Acesso em: 13 jan.2019.

SKLIAR, Carlos; SOUZA, Regina Maria de. A interpelação da objetividade científica e os debates sobre as igualdades e as diferenças: o contexto das atuais discussão. 2007. Disponível em: http://www.lite.fe.unicamp.br/cursos/nt/ta2.1.htm. Acesso em: 16 ago. 2018.

SOARES, Luiz Eduardo. Desmilitarizar: segurança pública e direitos humanos. São Paulo: Boitempo, 2019.

VICE BRASIL. O Mito de Bolsonaro: o que pensam e como se organizam seus apoiadores? Brasil: YouTube, 3 agosto 2018. 1 vídeo (25 min). Disponível em: https://www.youtube.com/watch?v=bBg6vkwcOxM. Acesso em: 12 jun. 2019.

ZAN, Dirce; MAZZA, Débora. Formação de professores no contexto atual: os desafios apontados pelo Professor António Nóvoa. In: KRAWCZYK, N. (org). Escola pública: tempos difíceis, mas não impossíveis. Campinas: FE/UNICAP; Uberlândia: Navegando, 2018, p. 187-204. Disponível em: https://docs.wixstatic.com/ugd/35e7c6_b164114ceb7e443a929679a4b417d7b9.pdf. Acesso em 12 jan. 2019.

ZINET, Caio. Relatório critica cortes no orçamento, privatização e militarização na educação brasileira. EI Centro de referências em educação integral. Brasil, 16 set. 2015. Disponível em: https://educacaointegral.org.br/reportagens/relatorio-critica-cortes-orcamento-privatizacao-militarizacaoeducacao-brasileiral. Acesso em: 5 jul. 2019. 